Cuad. Invest. Filol., 43 (2017), 167-190. http://doi.org/10.18172/cif.3004

\title{
HOMENAJE A CHAPLIN Y AL CINE BURLESCO EN LA TRILOGÍA NOVELESCA DE JARDIEL PONCELA
}

\author{
Cécile François \\ Universidad de Orleans, Francia \\ cecile.francois@univ-orleans.fr
}

\begin{abstract}
RESUMEN: Este artículo analiza la influencia del cine burlesco de los años 20 en la trilogía novelesca de Enrique Jardiel Poncela en la que se multiplican las referencias y alusiones a Charles "Charlie" Chaplin y al personaje mítico creado por él. En esta obra se aprecia el afán del escritor madrileño por adaptar el gag chapliniano al ámbito de la novela e intentar proponer una versión femenina de Charlot. Este homenaje a Chaplin pone de manifiesto el vínculo entre las ideas estéticas de Enrique Jardiel Poncela y las del maestro del cine cómico al que los vanguardistas de principios de siglo consideraban un icono de la modernidad.

PALABRAS CLAVE: Jardiel Poncela, Charlie Chaplin, gag, cine burlesco, vanguardia.
\end{abstract}

\section{HOMMAGE À CHAPLIN ET AU CINÉMA BURLESQUE DANS LA TRILOGIE ROMANESQUE DE JARDIEL PONCELA}

RÉSUMÉ: Cet article propose une analyse de l'influence exercée par le cinéma burlesque des années 20 sur la trilogie romanesque de Jardiel Poncela, dans laquelle l'auteur multiplie les références et les allusions à Charles "Charlie » Chaplin, ainsi qu'au personnage mythique qu'il a créé. Cette œuvre révèle la volonté de l'écrivain madrilène d'adapter le gag chaplinesque à l'univers du roman et de proposer une version féminine de Charlot. Cet hommage à Chaplin souligne le lien tissé entre les idées esthétiques de Enrique Jardiel Poncela et celles du maître du burlesque que les artistes de l'avant-garde considéraient comme une icône de la modernité.

MOTS-CLÉS: Jardiel Poncela, Charlie Chaplin, gag, cinéma burlesque, avant-garde.

Recibido: 20/05/2016. Aceptado: 16/02/2017 


\section{Introducción}

En 1928, cuando Enrique Jardiel Poncela emprende la redacción de la primera novela de la trilogía ${ }^{1}$, el cine ya ha cobrado carta de naturaleza por ser un medio de expresión universal capaz de llegar a todo tipo de público, cualquiera que sea la nacionalidad de los espectadores. De hecho, en la década de los años 20, el cine ya ha dejado de ser un mero entretenimiento o una diversión de feria para convertirse, no solo en un nuevo arte, sino en un crisol al que van a parar todas las vanguardias ${ }^{2}$. En aquella época, a todos los escépticos que dudaban de que el cine pudiera considerarse un arte, el poeta cubista Max Jacob contestaba tomando como modelo a Charles Chaplin: "L'immortel Charlot, qui transforme la réalité en miracle, prouve à lui seul que cet art existe” (Lista 2005: 49)33.

Esta cita da fe de la admiración que sentían los artistas vanguardistas por Chaplin, a quien muchos no dudaban en tributar homenaje, sea literaria o plásticamente ${ }^{4}$. En España, mientras Federico García Lorca y Rafael Alberti manifestaban preferentemente su entusiasmo por Buster Keaton ${ }^{5}$, Ramón Gómez de la Serna publicaba un texto titulado "El charlotismo" que no dudaba en presentar "como un momento histórico del humor del planeta” (Riambau 2000: 39) ${ }^{6}$. Admirado y reverenciado tanto por el público como por los críticos e intelectuales del mundo entero, Chaplin alcanzó, a partir de 1914, con los treinta y cinco cortometrajes de la serie Keystone, una cota de popularidad tan alta que su personaje se convirtió en

1. La trilogía consta de tres novelas redactadas entre 1928 et 1930 . Se titulan respectivamente: Amor se escribe sin hache (1928), ¡Espérame en Siberia, vida mía! (1929) y Pero... ¿ ¿hubo alguna vez once mil vírgenes? (1930). Siempre que a lo largo de este artículo se citen las obras de Jardiel Poncela se hará de manera abreviada: Amor, Espérame, Vírgenes.

2. "A l'Est comme à l'Ouest, le cinéma est un creuset où toutes les avant-gardes aboutissent et se fondent pour générer un langage dicté par la nécessité sinon nourri par le hasard” (Gaston Haustrate 1997: 53).

3. "El inmortal Charlot, que convierte la realidad en milagro, demuestra por sí solo que este arte existe" (las traducciones al castellano de las citas francesas son mías).

4. La revista Beaux Arts reproduce algunas obras pictóricas en las que aparece la inconfundible figura de Charlot, como "La Joconde amoureuse de Charlot" y "Charlot cubiste" de Fernand Léger, junto con obras de Erwin Blumenfeld o Rudolf Ausleger (2005: 49-57).

5. El poema de Lorca se titula "El paseo de Buster Keaton”. Rafael Alberti, por su parte, evoca la película Go West (El rey de los cowboys, 1925): "Buster Keaton busca por el bosque a su novia, que es una verdadera vaca”. Alberti escribirá también un poema en honor a Chaplin titulado: "Cita triste de Charlot" (datos sacados del libro de Cyril B. Morris 1993: 29).

6. A propósito de Ramón Gómez de la Serna, Andrés Amorós señala que "su fervor por Chaplin le llevó a intentar estrenar una ópera, Charlot, con música de Bacarisse, en 1933, en Buenos Aires” (1991: 210). 
un verdadero mito (Bordat 1997: 52). En tal contexto, cuesta imaginar que Enrique Jardiel Poncela, siendo cinéfilo y espectador asiduo, además de gran admirador de Ramón Gómez de la Serna, no se haya sentido atraído por el cine de Chaplin y las soluciones que aportaban los gags de Charlot a la crisis de la representación que era, por aquel entonces, objeto de debate en muchos países europeos.

\section{Las referencias a Chaplin y al personaje de Charlot}

Ya en el prólogo de Amor se escribe sin hache, Jardiel revela al lector los sentimientos que experimenta hacia Chaplin, a quien considera el maestro indiscutible del cine de la época: "El hombre a quien más admiro, al que considero como el más importante del mundo, en el pasado y en la actualidad, es Charlie Chaplin (Charlot), verdadero genio de todas las épocas” (Amor: 85). Es más, cuando se reedite la novela en 1933, Jardiel volverá a expresar su entusiasmo en una nota a pie de página: "Y hoy, después de haber conocido a Charlot de cerca, me confirmo en mi opinión” (Amor: 85; énfasis del autor). Esta reiteración demuestra el afán de Jardiel por reafirmar su afecto y respeto al creador de Charlot en un momento en que los intelectuales españoles empezaban a desestimarlo, reprochándole la sensiblería y la cursilería de su personaje:

En los ambientes de vanguardia, sin embargo, iba extendiéndose una creciente antipatía a Charlot, considerado, cada vez más, un humorista burgués, contraponiéndolo al gran Keaton. [...] A fines de los años veinte, los vanguardistas españoles habían vuelto mayoritariamente la espalda a Charlot, por su sentimentalismo (Amorós 1991: 211-212).

A finales de los años 20, Jardiel era uno de $\operatorname{los} \operatorname{pocos}^{7}$ que seguían manifestando su admiración por el actor y su personaje más emblemático, mencionándolos varias veces en la trilogía. Es interesante notar que, en aquella época, el público no establecía una diferencia clara entre Chaplin y Charlot, a los que solía confundir. Igual pasa en iEspérame en Siberia, vida mía! cuando el protagonista evoca la tumultuosa vida sentimental de Chaplin: “¿Será verdad que Charlot se casa en terceras nupcias como aseguraba el Journal que compré en Marsella?” (297, énfasis del autor). Cierto es que esta equivocación se explica fácilmente por el marco en que se inscribe la reflexión del protagonista. De hecho, esta es

7. Con Alberti y Lorca, según Andrés Amorós (1991: 213). 
una pregunta que se le ocurre en el momento más inoportuno, cuando ya lleva varias horas nadando en el mar con pocas esperanzas de poder alcanzar la orilla. En tal aprieto, ya se comprende que Mario no establezca ninguna diferencia entre el actor y el personaje que Chaplin encarna en la pantalla.

Sin embargo, más allá de estos problemas de identidad, lo que llama la atención del lector es sobre todo lo incongruente de la situación del protagonista, el cual, en vez de preocuparse por su supervivencia, se entretiene con detalles tan intrascendentes y frívolos como la boda de los famosos. Lejos de sentir angustia en este trance, el personaje jardielesco se comporta con la misma indiferencia o impavidez que suele caracterizar a Charlot. Esta observación viene corroborada por otro episodio de la trilogía. En Amor se escribe sin hache, esta vez es el padre de la protagonista quien permanece impertérrito en una situación sumamente dramática:

[...] sir Patricio cayó al lago. Sabía nadar y era hombre sereno, así es que, al encontrarse en el agua, sacó su pipa y pretendió llenarla de tabaco, pensando que alcanzaría la orilla nadando únicamente con las piernas. Por desgracia había olvidado que el reúma tenía sus piernas inmovilizadas. Y lord Brums se quedó en el fondo del lago [...]. (Amor: 106).

Cierto es que sir Patricio tipifica de manera caricaturesca al inglés desenvuelto y flemático, pero su impasibilidad lo entronca también con ciertas figuras del cine mudo de los años 20 al que Jardiel Poncela era tan aficionado ${ }^{8}$. De hecho, lord Brums recuerda a todos aquellos personajes encarnados por Charley Chase, Charlie Chaplin y otros actores cómicos, en los que las tribulaciones o los accidentes no hacían mella. Al leer el episodio de la muerte de sir Patricio, al lector le viene a la mente la famosa secuencia de Charlot presidiario ${ }^{9}$, en que un socorrista se tira al agua con el propósito aparente de rescatar a una mujer que se está ahogando. Pero, ya en el mar, en vez de atender a la bañista desesperada que agita los brazos en vano, él se tumba boca arriba para fumar tranquilamente un cigarrillo. Hay en los personajes de Jardiel Poncela, igual que en las grandes

8. En un artículo de la revista Brújula del cine, Carlos Fernández Cuenca deja constancia de la afición de Jardiel a este nuevo modo de expresión: “Como hombre representativo de nuestra generación Enrique amaba al cine desde mucho antes de pensar en relacionarse con él de otra manera que como espectador. Algunas películas que le gustaban volvía a verlas a los pocos días del estreno” (“Enrique Jardiel Poncela y el cine”, artículo reproducido en el libro de Eva Jardiel 1999: 285).

9. The Adventurer (en español Charlot presidiario) es un cortometraje realizado por Charles Chaplin para la Compañía norteamericana Mutual. Se estrenó el 22 de octubre de 1917. 
figuras del cine burlesco, una especie de inadaptación al mundo, un desfase cómico entre su actitud y el comportamiento que el lector (o el espectador) se espera lógicamente de ellos.

En ¡Espérame en Siberia, vida mía!, Jardiel no se contenta con colocar a su protagonista en una situación parecida a las de los cortometrajes burlescos más famosos, sino que utiliza el nombre del personaje de Chaplin como término comparante para elaborar algunos símiles. Da fe de ello este ejemplo: "La piculina del condado de Sussex, ya en la decadencia, ya bastante pasada -casi tan 'pasada' como una película de Charlot- tuvo que mostrarse amabilísima” (Espérame: 336). Valiéndose de los recursos de la dilogía, Jardiel juega con las dos acepciones del verbo "pasar". Notemos al respecto que, si bien el sema de desgaste afecta negativamente al elemento comparado -es decir a la prostituta inglesa-, en cambio la noción de reiteración incluida en el adverbio "tan" contribuye a enaltecer las películas de Chaplin, cuyo éxito era directamente proporcional al número de proyecciones en las salas. El desgaste de los celuloides de Charlot atestigua la afición de un público numeroso y entregado que no se cansa de ver una y otra vez las aventuras de su héroe favorito, el vagabundo astuto y ágil que pasea por la vida como un funámbulo.

Además de las referencias directas al personaje de Charlot, el narrador de la trilogía esmalta su relato con alusiones que pueden interpretarse como otros tantos guiños al lector cinéfilo. Así por ejemplo, el protagonista de Amor se escribe sin hache da este famoso giro de ciento ochenta grados en un solo pie tan característico del personaje de Chaplin. Francis Bordat explica que este movimiento tan raro de Charlot, provocado por la cuadratura de la pantalla, le permitía mantenerse durante el mayor tiempo posible delante de la cámara sin frenar su impulso (1992: 52). Aquí, dejándose llevar por el movimiento, Zambombo no se contenta con una sola vuelta sino que ejecuta un giro triple sobre sí mismo, demostrando su sentido del equilibrio, así como la energía desbordante que lo caracteriza: “dio tres vueltas sobre sí mismo apoyado en uno de sus tacones” (Amor: 235).

Si Buster Keaton se mereció el calificativo de "autómata” y Harry Langdon el de "sonámbulo", el nombre de Charlot por su parte viene asociado con la palabra "acróbata" (Revault d'Allonnes: 1997: 39) ${ }^{10}$. En Shanghaied, ${ }^{11}$ Charlot

10. En su libro, Adolphe Nysenholc recuerda estos versos de Maiakowski : "Sur l'écran vole / Charlot muni d'ailes / Le céleste Charlot" ("Por la pantalla vuela / Charlot provisto de alas / el celestial Charlot”) (1979: 186).

11. Charlot marinero, 1915. 
lleva una bandeja llena de platos en un barco que se tambalea peligrosamente. De pronto resbala, pierde el equilibrio, pero logra recuperarlo por los pelos tras un espectacular salto mortal que ejecuta sin soltar la bandeja, la cual se mantiene en una posición horizontal, por lo que no cae un solo plato. Asimismo, en His Favourite Pastime ${ }^{12}$, Charlot, en estado de ebriedad avanzada, cae desde lo alto de la escalera sin hacerse daño, con otro salto mortal gracias al que va a parar directamente a un sofá mullido. Astuto y ágil, acróbata y funámbulo, Charlot domina el espacio, aunque muchas veces su destreza y su flexibilidad están respaldadas por un valioso coadyuvante: el azar, que Petr Král equipara a una especie de "ángel custodio” del héroe burlesco (1984: 78).

En Amor se escribe sin hache, son dos las ocasiones en que el protagonista se ve obligado a ejecutar un salto mortal. Pero, a diferencia de Charlot, lo que lo mueve a sacar partido de su agilidad no es la ebriedad ni tampoco el mar embravecido, sino el deseo de complacer a la mujer amada. Solo por congraciarse con ella y fascinarla, consiente en correr el riesgo de descalabrarse. Zambombo dista mucho de ser tonto e irreflexivo; sabe que no tiene ninguna experiencia de la acrobacia, pero el caso es que Sylvia Brums acaba de notificarle que ella "sería incapaz de amar a un hombre que no supiese dar el doble salto mortal” (Amor: 170). Víctima de su propio deseo, Zambombo no tiene más remedio que hacer gala de sus dotes de volatín:

Y comprendiendo que no conducía a nada el dilatar la demostración, se subió sobre la mesa [...] y se lanzó al parquet de cabeza, con vigoroso impulso de los músculos tibiales y tensorios de la fascia lata.

Dos vertiginosos giros en el aire y Zambombo cayó de pie. Acababa de dar el primer salto mortal de su existencia (Amor: 171).

Cabe notar que el campo léxico de la fisiología enfatiza el aspecto técnico de la hazaña de Zambombo, quien parece controlar cada músculo de su cuerpo como un auténtico atleta profesional. Agilidad, flexibilidad, dominio de sí mismo... y azar favorable, ¿no son estos los principales ingredientes de las películas de Chaplin?

Poco después de encandilar a lady Brums con su espectacular doble salto mortal, Zambombo se dispone a reiterar la proeza para obtener los favores de Mignonne Lecoeur, a quien acaba de encontrar en el tren que lo lleva a París. Pero, esta vez, ya no actúa por imposición o capricho de su pareja. En unas cuantas semanas, el Zambombo torpe y cohibido del principio se ha convertido en un

12. Charlot extremadamente elegante, 1914. 
seductor avezado que decide deslumbrar a la joven francesa con sus acrobacias, sin que ella se lo pida. Lo que le mueve a adoptar una actitud entre despreocupada e intrépida es ahora el deseo de "figurar a los ojos de Mignonne como un hombre excepcional, muy baqueteado ya por la vida” (Amor: 236). El salto mortal se inscribe así en una estrategia destinada a potenciar sus posibilidades de éxito:

«Un toque más y me echa los brazos al cuello subyugada», se dijo.

Y calculó que el toque estaba en dar un doble salto mortal, aquel doble salto mortal que nunca había intentado hasta el día que lo ejecutó para rendir la complicada fortaleza de Sylvia Brums.

Se recogió en sí mismo, hizo un poderoso esfuerzo muscular y se lanzó al espacio (Amor: 237; énfasis del autor).

Pero, esta vez, el azar no se muestra tan favorable. Igual que en las mejores películas burlescas, y más tarde en los dibujos animados de Tex Avery, el cuerpo del protagonista se desvía de su trayectoria y, pasando por la ventana abierta del compartimento, va a parar a la vía férrea. Sin embargo, nada puede destruir al héroe burlesco, y Zambombo se levanta del suelo, sorprendido quizá, pero satisfecho de no haber salido malparado del trance: "Para la primera vez que me caigo de un expreso en marcha, no lo he hecho mal del todo” (Amor: 238). Volvemos a encontrar en el personaje de Zambombo, igual que en las figuras de sir Patricio o Mario Esfarcies, esa extraña impasibilidad frente a los peligros del mundo que caracteriza al personaje burlesco. El comentario de Zambombo muestra que el accidente forma parte de la experiencia que él debe adquirir, al igual que el salto mortal o el lance amoroso. De hecho, al personaje burlesco nada le parece nunca dramático.

\section{Jardiel y el gag chapliniano}

Si se comparan ahora las dos secuencias anteriormente mencionadas, se aprecia una clara diferencia que no afecta tan solo al desenlace o a la actitud del héroe ante el reto planteado. Lo que resalta del cotejo de los dos episodios es una clara evolución en el tratamiento de la peripecia, así como en la dimensión del espacio narrativo que le dedica el narrador. En el primer caso, la hazaña se lleva a cabo rápidamente y el lance se relata en unas cuantas líneas. En cambio, en la secuencia del tren, el salto mortal ya no viene tratado tan solo como una mera demostración de destreza, sino como un verdadero gag. El espacio del vagón se convierte en un decorado de película burlesca, cuyas potencialidades cómicas se 
exploran de manera sistemática. De hecho, la escena de la seducción de Mignonne Lecoeur se configura como una sucesión de "microgags" que se encadenan sin interrupción hasta el desenlace. Cabe notar que estos forman un conjunto claramente acotado que fácilmente se podría desgajar del resto del relato. En rigor, el argumento central de la novela no perdería un ápice de su coherencia si se suprimiera el episodio. En cambio, se le privaría al lector de un momento de puro delirio cómico en consonancia con el cine burlesco de la época.

Ya antes de dar el famoso salto mortal, Zambombo sabe que tiene que hacer gala de mucha inventiva y jocosidad si quiere seducir a Mignonne, con lo que Jardiel aprovecha otra vez la oportunidad para rendir homenaje a Charlie Chaplin y a sus dotes de malabarista. Un claro ejemplo de la destreza de Charlot nos lo brinda el cortometraje The Champion ${ }^{13}$, en que el protagonista juega con unas mazas que lanza al aire a riesgo de descalabrarse a cada momento. Jean Mitry habla al respecto del deslumbrante ballet coreografiado por Chaplin con las pesas, el trapecio y las anillas, saltando, bailando, haciendo cabriolas, como un funámbulo en la cuerda floja ${ }^{14}$. Siguiendo el modelo de Charlot, Zambombo luce sus dotes ante Mignonne intentando "hacer juegos malabares con tres pesados ceniceros de cristal y plomo” (Amor: 234) ${ }^{15}$. Por supuesto, la actuación del héroe jardielesco entra en una estrategia de seducción equiparable a la de Charlot boxeador, quien hace alarde de virtuosismo para enamorar a Edna.

Observamos que la proeza del héroe logra surtir efecto, ya que Mignonne "lo observ[a] fijamente, con un estatismo de embeleso" (235). Esta fascinación se explica también por el ritmo vertiginoso de la escena que aturde a la hermosa viajera. De hecho, pronto el ballet ingrávido se convierte en vorágine devastadora, digna de los primeros cortometrajes de la compañía Keystone en la que debutó Chaplin:

[Zambombo] atravesó su cigarro con un palillo de dientes, lo hizo girar sobre aquel eje y dispersó la lumbre por el mantel, el suelo, el vestido y el escote de Mignonne. [...]

Y tirando su reloj contra una de las lámparas, la hizo polvo.

El jefe del restaurant se acercó entonces con una notita recién arrancada de un block de papel. Zambombo la cogió, construyó una bola con ella y se la comió sin

13. Charlot campeón de boxeo, 1915.

14. Charlot "mène un étourdissant ballet avec les poids et les haltères, le trapèze et les anneaux, sautant, dansant, valsant de l'un à l'autre comme un équilibriste sur la corde raide” (Mitry 1972: 79).

15. También demuestra tener buenas aptitudes cuando "acab[a] lanzando el disco con los tres ceniceros” (Amor: 234). 
masticarla. Después imitó el cacareo de una gallina, abrió la boca para declamar a grito seis versos de «La Divina Comedia» y dio tres vueltas sobre sí mismo apoyado en uno de sus tacones. [...]

Y Zambombo se apresuró a [...] romper las restantes lámparas del vagón a una velocidad increíble (Amor: 235; cursiva del autor).

Es interesante notar que, si comparamos esta secuencia con la mayor parte de los cortometrajes burlescos de Mack Sennett -los cuales solían acabar en un caos generalizado-, la acción queda aquí perfectamente controlada por Zambombo. De hecho, el héroe no se deja llevar por sus impulsos y logra conservar el control de la situación (a diferencia de Fatty o de "el Gordo y el Flaco", cuyo comportamiento estrafalario traduce una verdadera inadaptación al mundo). Zambombo sabe que puede pararse en cualquier momento, esto es cuando haya alcanzado su meta, que consiste en "mord[er] fieramente los labios de Mignonne y traslad[arla] en volandas al coche contiguo" (Amor: 235).

En el libro que dedica a la obra de Buster Keaton, Jean-Pierre Coursodon analiza los mecanismos del gag mostrando que su meta es jugar con las expectativas del espectador "en organisant le déroulement du gag de manière, soit à retarder le moment où cette attente sera satisfaite, soit à la tromper en substituant une chute imprévue à celle escomptée" (1973: 272) ${ }^{16}$. Esta disyunción entre las conjeturas del público y el remate sorpresivo del episodio constituye el meollo de una de las mejores secuencias cómicas de The Idle Class ${ }^{17}$. El gag se desarrolla aquí de manera clásica en tres etapas, según el modelo de la historieta cómica. Los dos primeros movimientos (planteamiento y desarrollo) corresponden a la preparación o condicionamiento del espectador. En la película, Chaplin hace de burgués rico y juerguista a quien abandona su esposa, exasperada por las calaveradas de su marido y su afición a la bebida. Ya solo en su casa, este recorre melancólicamente la habitación, deteniéndose finalmente ante una mesita en la que se hallan unas cuantas botellas de licor junto con un retrato de su mujer. El protagonista toma la fotografía, la mira tristemente y se da la vuelta para colocarla de nuevo en la mesa. Y luego permanece inmóvil, de espaldas a la cámara, como abrumado por la pena y el remordimiento.

Durante esta primera fase, llamada por Coursodon "fase de conjunción" o de "normalización”, Charlie Chaplin ha focalizado nuestra atención en la escena

16. organizando el desarrollo del gag con el fin de aplazar el momento de satisfacer dichas expectativas, o de defraudarlas sustituyendo un remate completamente distinto al desenlace esperado.

17. Vacaciones, serie First national, 1921. 
de la ruptura conyugal, para que interpretemos lógicamente el plano corto de los hombros estremecidos del personaje como la señal de una profunda aflicción. Pero, de repente, descubrimos que no son sollozos los que provocan este temblor. Abordamos entonces la última fase, la de la “disyunción”, cuando Chaplin se da la vuelta mirando hacia la cámara y agitando una coctelera. Este ejemplo concuerda exactamente con la definición del gag formulada por Jean-Pierre Coursodon:

Structure dynamique et démonstrative dans laquelle, à un exposé objectif des données, succède leur exploitation dans une certaine direction, puis le détournement de cette direction dans un sens inattendu, ce qui entraîne la chute, véritable 'résolution' qui serait impossible sans l'enchaînement logique et irréversible des prémisses au développement et du développement au terme du cycle (1973: 270) ${ }^{18}$.

La fase de disyunción, al introducir un sentido nuevo, destruye el sentido primigenio inducido por la fase de normalización, imponiendo así una nueva lectura al espectador. Como señala Aldo Lombezzi, una construcción de tipo disyuntivo altera la linealidad semántica del sintagma descriptivo para instaurar una especie de "juego semántico": "Ce type de message possède un caractère 'anti-analogique' par rapport à l'action, laquelle reste bloquée. Le seul mouvement qu'il développe est un mouvement (rétroactif) de sens" (Lombezzi 1983: $53)^{19}$. De hecho, esta operación de reinterpretación del gesto de Charlot es la que debe llevar a cabo el espectador para apreciar los efectos cómicos del gag, el cual no cobra pleno sentido sino con ese movimiento de revisión de la escena anterior.

En Pero... ¿hubo alguna vez once mil vírgenes? (1930), Jardiel Poncela demuestra que ha comprendido perfectamente los mecanismos del gag a través de una escena que constituye un cálido homenaje a Charlie Chaplin. Al final de la novela se desarrolla una entrevista entre Vivola y don Pedro, en la que este procura convencer a su amada de la sinceridad de sus sentimientos. Pero, lejos de manifestar alguna emoción ante esta declaración apasionada, ella mira desdeñosamente al donjuán poniendo "en la electricidad ardorosa de sus pupilas la frialdad de un aislador de porcelana. Y en sus palabras, una más fría frialdad”

18. Estructura dinámica y demostrativa en la que, a una presentación objetiva de los datos, sucede la explotación de los mismos en determinado sentido, antes de desviarse a otra dirección totalmente imprevista, lo cual lleva al remate cómico, verdadera 'resolución', que resultaría imposible sin el encadenamiento lógico e irreversible de la premisa al desarrollo, y del desarrollo al fin del ciclo.

19. “Este tipo de mensaje es de índole ‘antianalógica’ con respecto a la acción, la cual queda bloqueada. El único movimiento es un movimiento (retroactivo) de sentido” (Lombezzi, 1983: 53). 
(Vírgenes: 456). La actitud de Vivola provoca en don Pedro una viva reacción de despecho que se va convirtiendo en rencor: "La odiaba. La odiaba todo lo que la había amado" (456).

Irritado, el seductor intenta sosegarse paseando lentamente por la habitación. En este momento preciso es cuando el narrador introduce en el relato un indicio cuyo alcance solo se entenderá retrospectivamente pero que, de momento, el lector interpreta sin duda como una señal de nerviosismo por parte del personaje. Valdivia saca, en efecto, de su pitillera un cigarrillo que no puede encender porque su mechero no funciona. Este es el elemento que prepara el paso de una isotopía a otra. Hasta ahora, la atención del lector ha sido centrada en la ansiedad del personaje que sabe que su suerte depende de la reacción de Vivola. Ahora bien, en el momento preciso en que esta rechaza el amor de Valdivia, el narrador menciona "un pequeño cuadro votivo, incrustado en una hornacina de la pared, que representaba a Santa Ana d'Auray y ante la cual latía la llamita de una lamparilla de aceite" (Vírgenes: 456). Igual que en The Idle Class, don Pedro se acerca al retrato y "permanec[e] allí unos momentos, dándole la espalda a Vivola” (457).

A ejemplo de Chaplin, Jardiel "encuadra” a su personaje de modo que no le veamos la cara. Esto crea una especie de suspense, una expectación durante la cual el lector se interroga: ¿Qué estará haciendo? ¿Se habrá vuelto para disimular unas lágrimas de dolor o de rabia? O bien, en esta atmósfera de recogimiento y fervor religioso, ¿estará rezando ante la imagen de Santa Ana e implorando ayuda al Cielo? La espera no se prolonga mucho y la explicación llega inesperada e iconoclasta: "Pedro encendía su cigarrillo en la llamita de la hornacina" (457). El gesto de don Pedro aniquila el ambiente recogido y devoto del principio de la secuencia, trastocando los planteamientos apriorísticos del lector. Según apunta Sylvain du Pasquier, la función perturbadora del gag responde con su lógica propia a la función precedente (esto es la función normativa) (1970: 143). Pero, en realidad, estas dos funciones solo se contradicen de manera aparente, puesto que, al fin y al cabo, la disyunción es simplemente una lógica que la función de normalización ya entrañaba en sí implícitamente.

Señala Frédéric Favre que una de las consecuencias de la utilización del gag es la introducción de un principio de igualdad entre todos los participantes (1995: 2). El cine burlesco no deja títere con cabeza y hasta los personajes femeninos suelen salir malparados de la aventura. Muchas veces las mujeres de los cortometrajes son, o bien tontorronas que tienen que aguantar las impertinencias del protagonista, o tarascas que se lían a palos con sus congéneres propinándoles, si 
procede, una buena paliza. Basta con mencionar a la esposa tiránica de Charlot en Pay Day, la cual espera a su marido juerguista con un rodillo de amasar en la mano. Sin embargo, muy pocas son las figuras femeninas que protagonizan una película entera, siendo la más conocida Marie Dresslers, quien comparte cartel con Chaplin en Tillie's Punctured Romance, y a la que los franceses dieron el nombre de Lolotte ${ }^{20}$.

\section{Una apuesta: la versión femenina de Charlot}

En la obra que dedica al cineasta francés Louis Feuillade, Francis Lacassin señala que los norteamericanos ya se habían acercado al género cómico, en su versión femenina, con la serie Totoche. En ella se apreciaban los mismos efectos cómicos que en las películas de Charlot, pero el defecto de estos cortometrajes era que los protagonizaba un personaje femenino harto vulgar. Por eso, pronto comprendieron que era inútil remedar a Ben Turpin, Buster Keaton, Fatty, y sobre todo a Charlot, con una réplica femenina (Lacassin 224). Al leer Amor se escribe sin hache, podemos preguntarnos si Jardiel no quiso afrontar el reto. De hecho, en una obra que presenta una galería de personajes femeninos a cuál más caricaturesco, podía resultar tentador convertir a la sugestiva mujer fatal en muñeco burlesco, aproximándola a la figura de Charlot. Es, al menos, lo que sugiere uno de los episodios de Amor se escribe sin hache, en que la aristocrática Sylvia Brums hace el ridículo después de una noche de juerga.

Para convertirla en personaje cómico, el narrador echa mano de uno de los rasgos característicos del Charlot de los primeros cortometrajes. Adolphe Nysenholc recuerda al respecto que, desde His Favourite Pastime hasta Limelight en que el viejo Calvero busca consuelo en el alcohol, Charlot se tambalea de película en película, manteniendo a duras penas el equilibrio (1970: 106) ${ }^{21}$. En la pantalla, cuando está ebrio, Charlot no aparece tan solo bajo la apariencia del famoso vagabundo. Para hacer de borracho, Chaplin indica que se inspiró en Max Linder, un actor del cine cómico francés que sobresalía en la interpretación de dandis

20. Esta película de 1914 se estrenó en Francia con el título de La Romance de Charlot y Lolotte, el cual coloca en un plano de igualdad a los dos protagonistas, mientras que el título americano menciona únicamente al personaje femenino. En España se aprecia cierto titubeo a la hora de determinar a quién le toca el papel estelar, puesto que, si a menudo se traduce por Aventuras de Tillie: el romance de Charlot, también puede encontrarse tan solo la forma abreviada El romance de Charlot, lo cual le resta protagonismo al personaje femenino.

21. Esteve Riambau señala por su parte que "las borracheras son frecuentes en los primeros cortometrajes de su filmografía”, citando media docena de títulos de la serie Keystone (Riambau 2000: 59 y sig.). 
achispados (Mitry 1972: 230). Desde The Rounders (1914) hasta The Idle Class (1921), pasando por One A.M. (1916), el personaje de Chaplin pasea su elegante figura oscilante, tropezando en diversos y alevosos obstáculos que le estorban el paso hacia su cama. Pues bien, en Amor se escribe sin hache, el narrador describe a una lady desaliñada y ebria que vuelve de madrugada al selecto Hotel Crillon de París. La refinada aristócrata ofrece en ese momento un espectáculo entre cómico y lamentable: "Sylvia traía el vestido rasgado, la capa colocada a guisa de refajo, los zapatos en las manos, las medias haciendo el oficio de guantes y la cabeza cubierta con un bidón vacío de petróleo. De vez en cuando recitaba trozos de Molière y de Ibsen” (Amor: 280).

Jardiel parece haberse inspirado aquí en The Rounders, un cortometraje en que Charlot, vestido de frac, con el sombrero de copa ladeado y la capa echada al hombro como un torero, vuelve completamente borracho al Majestic Hotel, tras una noche de juerga. Pero, sorpresivamente, en Amor se escribe sin hache el autor no saca partido de este arranque prometedor y despacha la escena en unas cuantas líneas. Sin embargo, podemos pensar que Jardiel era consciente del potencial cómico de la escena ya que, en la novela siguiente, lo explota al máximo. Así, en ¡Espérame en Siberia, vida mía!, la ebriedad del protagonista provoca una serie de peripecias burlescas que se encadenan a lo largo de más de diez páginas. En este caso, el punto de partida no es muy distinto al de la escena de Amor se escribe sin hache y la descripción del personaje de Mario Esfarcies presenta muchas afinidades con la de lady Brums:

Traía el smoking en bandolera con las mangas atadas sobre el pecho. Media pernera del pantalón y media pechera de la camisa habían quedado olvidadas Dios sabe en qué misteriosos parajes de la ciudad o del extrarradio. Su mano derecha tremolaba la corbata y su mano izquierda arrastraba, con el consiguiente tumulto férreo, una silla de tijera de paseo público. Finalmente, llegaba absolutamente descalzo y jugando al fútbol con su zapato diestro (Espérame: 134).

A todas luces, el retrato de Mario es el eco del de lady Brums, pero parece como si a Jardiel le desagradara valerse de los recursos del cine burlesco para desmitificar a su heroína. De hecho, ya en el umbral de la trilogía, la escena del aseo de Sylvia hubiera podido dar al narrador la oportunidad de explotar la comicidad de la situación en que se encuentra la protagonista. Recordemos que, en la primera secuencia de Amor se escribe sin hache, Sylvia, tendida en una otomana 
"[en] la postura de los condenados al suplicio llamado de la escalera”, es asaltada por una nube de empleados que convierten su habitación en una cámara de tortura:

La masajista Asunción le pellizcaba el rostro.

[...] La doncella Juanita le estropeaba los ojos.

Todas las mañanas, desde hacía unos años, aquellas operaciones se repetían y sólo cambiaba los nombres de las personas que manoseaban a lady Sylvia (Amor: 104105; énfasis mío).

Se nota que la dimensión dramática del seudosuplicio "de la escalera” viene neutralizada por la docilidad, cuando no el placer, con que lady Brums se somete a sus verdugos. El lector solo se fija por tanto en el aspecto divertido, algo grotesco de la escena, a la par que aprecia el arte con que Jardiel subvierte la famosa expresión popular: "Para estar bella, hay que sufrir". Esta escena recuerda una secuencia de Old Wives For News, una película de 1917, en la que el recurso a los insertos permitía a Cecil B. DeMille "trocear" el cuerpo de una mujer sometida al tormento de una cura adelgazante. El íncipit de Amor se escribe sin hache anticipa también en cierto modo la secuencia de apertura de Women de George Cukor, en que un grupo de mujeres de la alta sociedad, rodeadas de una multitud de masajistas y esteticistas en un salón de belleza, sufren lo indecible para recuperar esbeltez y lozanía.

Se ve, por tanto, que Jardiel permanece aquí dentro de los límites de la comedia. Habrá que esperar a la tercera novela de la trilogía para que el narrador someta la escena del aseo personal a un tratamiento burlesco, aunque tomando como víctima al protagonista masculino. Para poner en ridículo a Pedro de Valdivia, Jardiel se inspira en uno de los más famosos gags de Chaplin sacado de The Cure, un cortometraje de 1917. En Pero... ¿hubo alguna vez once mil vírgenes?, las relaciones del protagonista con su criado recuerdan la secuencia en que Charlot, amedrentado y cohibido, está esperando su turno, viendo cómo el fornido masajista maltrata a sus pobres pacientes. En esta reinterpretación del gag chapliniano, el narrador pone de relieve uno de los aspectos fundamentales del cine burlesco: la automatización de los gestos y la cosificación de los personajes, que son dos de los componentes básicos del humor jardielesco. Según comenta Guido Gola,

Que ce soit par la mécanisation des gestes et des comportements, par l'automatisation et la raideur des rapports à autrui et aux choses ou encore par des situations de conflit (avec des victoires et des défaites) avec la machine, 
le 'gag' produit toujours des effets comiques à partir d'une composante d'automatisme (Gola 1983: 26) ${ }^{22}$.

Esta concepción del gag es la que se aprecia en la secuencia de Pero... ¿hubo alguna vez once mil vírgenes? donde el diligente servidor repite una serie de movimientos precisos y técnicos. En esos momentos el criado modelo se asemeja a un robot que cumple infaliblemente con su deber, atendiendo solo a la eficacia de sus gestos. Paradójicamente, Ramón, siempre tan solícito con su amo, lo trata aquí sin ninguna consideración. De hecho, no bien lo vio salir de la piscina cuando corrió hacia él

y en cuanto lo tuvo en su poder, debajo del albornoz, le frotó y refrotó con indecible furia, como si quisiera pulimentarlo. [...]

Entonces el criado le ajustó un maillot, se lo echó a cuestas y, haciendo de anuncio de la 'Emulsión Scott', se encaminó hacia la puerta (Vírgenes: 292).

Entre las manos de su criado, don Pedro no tiene más consistencia que un fardo de ropa o un pedazo de carne. Pero es en la secuencia titulada "masaje" cuando el narrador lleva al extremo el proceso de deshumanización del personaje:

El criado depositó su carga en la mesa, calzóse unos gruesos guantes de crin y comenzó a golpear a Valdivia. Le golpeaba con las dos manos, insistiendo en la nuca, en la espalda y en el coxis; se subía encima para clavarle una rodilla en los riñones mientras le tiraba fieramente hacia atrás de la cabeza; le plegaba y le desplegaba las piernas con crujidos que presagiaban un próximo desprendimiento; le retorcía los brazos para retorcerle a continuación los pies y retorcerle inmediatamente después el cuello; le doblaba en dos como se dobla un libro; le doblaba en cuatro como se dobla un mapa. (Vírgenes: 292).

A diferencia de lo que pasa en el íncipit de Amor se escribe sin hache, en que el narrador se contentaba con sugerir la idea de deshumanización, el proceso de cosificación está aquí minuciosamente descrito y desarrollado a lo largo del episodio. En la secuencia del “masaje”, el campo léxico de la violencia ${ }^{23}$ traduce la brutalidad con que el servidor atiende a su amo, equiparándolo con

22. Sea mediante la mecanización de los gestos y comportamientos, la rigidez de las relaciones al otro, o situaciones conflictivas (incluyendo victorias y derrotas) con la máquina, el “gag” produce siempre efectos cómicos a partir de un componente de automatismo (Gola 1983: 26).

23. En esta secuencia del “masaje”, los dos verbos más empleados son “golpear” y “torcer”, además de una serie de términos y expresiones que traducen la violencia de la escena, tales como "clavar”, "tiraba fieramente” "plegaba y desplegaba”, “furia”, “masaje despiadado”, etc. 
un carnicero que intentase en vano ablandar un pedazo de carne demasiado duro. El proceso deshumanizador alcanza su punto álgido con dos símiles cuyo significado viene remarcado por el paralelismo de la construcción: "le doblaba en dos como se dobla un libro; le doblaba en cuatro como se dobla un mapa" (Vírgenes: 292). Con esta doble comparación, don Pedro se convierte en un muñeco de trapo o un pelele de goma que Ramón se complace en manosear, estrujar o retorcer a su antojo.

Cabe notar que el protagonista se deja doblar y triturar sin reaccionar ni protestar, aceptando que Ramón le obligue a adoptar las posturas más grotescas e inverosímiles igual que un muñeco descoyuntado. Esto es, en realidad, lo que aleja a don Pedro del modelo chapliniano, ya que Charlot en ningún momento se deja dominar por el masajista del balneario, sino que forcejea y responde a su verdugo “con unos movimientos que recuerdan poderosamente su tantas veces demostrada agilidad boxeística” (Riambau 2000: 234). El cotejo de las dos secuencias permite concluir que, a diferencia de Chaplin que representa un tipo de personaje activo, astuto y ágil, Jardiel echa mano de lo burlesco para convertir a su protagonista en un antihéroe grotesco. Por otra parte, al presentarse como un eco amplificado y deformado del gag chapliniano, el episodio del aseo personal del donjuán participa de la estética del cine cómico mudo que se fundamenta esencialmente en el exceso y la desmesura. Sin embargo, a pesar de la afición de Jardiel a este tipo de comicidad, hace falta reconocer que su narrador vacila siempre a la hora de convertir a la heroína en figura burlesca. Por eso, en la trilogía, igual que en las películas mudas de la época, los efectos cómicos de la farsa y de lo burlesco recaen preferentemente en los personajes masculinos.

\section{El cine cómico al servicio de las ideas estéticas de Jardiel}

En el momento en que emprende la redacción de su trilogía, Enrique Jardiel Poncela acaba de entrar en contacto con un grupo de jóvenes humoristas, encabezados por Ramón Gómez de la Serna, que pretendían elaborar un nuevo humor iconoclasta basado en la destrucción de estereotipos y la subversión de convenciones $^{24}$. En el prólogo de Amor se escribe sin hache, Jardiel reivindica el valor "purificador” y agresivo de la comicidad, resumiendo su declaración de intenciones con esta fórmula: “Siempre empleé la pluma como un insecticida” (75). Luego,

24. Este grupo integrado, entre otros, por Tono, López Rubio, Edgar Neville y Miguel Mihura, iba a formar lo que se ha dado en llamar "la otra generación del 27". 
empezado ya el relato de las desventuras de sus héroes, Jardiel reitera su profesión de fe a través de una aserción del narrador: "El humor es el zotal de la literatura" (260). Esta fórmula, muy parecida a un aforismo, manifiesta la ambición de la trilogía. Se trata, para el autor, de renovar la narrativa quitándole el lastre de lo manido y trillado que la está adulterando, lo cual pasa por la subversión de unas normas estilísticas y narrativas que él mismo calificaba de "mustias” o "putrefactas”. No cabe duda de que el joven escritor comprendió que el gag no solo ofrece una perspectiva innovadora de las cosas sino que, según afirma Petr Král, al desplazar maliciosamente una realidad apartándola de su sentido habitual, el gag también desvela el vacío en que se fundamentan las normas y convenciones ${ }^{25}$.

Entre las armas que esgrime el joven humorista contra la literatura trasnochada figura la parodia, una modalidad de la escritura cómica que permite poner en solfa todas las instituciones y combatir un lenguaje social y literario esclerotizado. Ahora bien, en la época de la redacción de la trilogía, las pantallas españolas acogían las hilarantes películas paródicas de Mack Sennett. Chaplin, por su parte, ya había propuesto a los espectadores una versión cómica de uno de los mitos más famosos de la literatura y del cine con su Charlie Chaplin’s Burlesque On Carmen, rodado en 1916, del que Esteve Riambau nos dice que

El éxito obtenido por las versiones que Cecil B. De Mille y Raoul Walsh hicieron de Carmen, respectivamente protagonizadas por la cantante de ópera Geraldine Farrar y la exótica Theda Bara, impulsó a Chaplin para realizar una parodia del célebre mito hispánico recreado por la novela de Prosper Mérimée y la ópera de Georges Bizet. El cómico la tituló explícitamente Charlie Chaplin’s Burlesque On Carmen y no dudó en reservarse personalmente el papel de don José (Riambau 2000: 189).

Si el mito de Carmen no parece haber inspirado a Jardiel, en cambio este se mofa abiertamente de Mérimée y de la visión anticuada del honor y de las tradiciones según vienen retratadas en Mateo Falcone o en Colomba (François 2010). En ¡Espérame en Siberia, vida mía!, más allá del motivo de la vendetta, es el tema de la honra en general el que sufre los efectos del humor disolvente de Jardiel. Es interesante notar al respecto que, casi en la misma época, Benjamín Jarnés organiza a su vez la "confrontación de dos mundos, dos siglos, dos géneros y dos ambientes morales” (Morris 1993: 166). En Escenas junto a la muerte, una novela un poco posterior a la última entrega de la trilogía, Jarnés imagina, en efecto, el encuentro de Chaplin y de Pedro Crespo en un capítulo titulado "Charlot

25. “en déplaçant perfidement une réalité par rapport à son sens coutumier, il dévoile -aussi et d'abordle vide sur lequel, à force d’être admise sans examen, risque de reposer toute convention” (Král 1984: 234). 
en Zalamea”. “La incursión de Chaplin en la sociedad del siglo XVI -explica Cyril B. Morris- le permite [al autor] interrogarse sobre los códigos morales y revisar una obra a la que se niega a venerar” (1993: 168).

Igual que su coetáneo, Enrique Jardiel Poncela escoge revisar el drama calderoniano injertándole una fuerte dosis de comicidad burlesca. La última novela de la trilogía pone en escena a una serie de maridos burlados de los que nos dice el narrador que "todos tenían una cosa que vengar: la honra”, añadiendo que "no hay que olvidar que a los vengadores de su honra sólo les empuja a la venganza la opinión ajena” (Vírgenes: 399). Por supuesto, la expresión “los vengadores de su honra” remite irónicamente al famoso drama de Calderón titulado El médico de su honra. Sin embargo, los maridos burlados de Pero... ¿hubo alguna vez once mil vírgenes? no tienen la grandeza trágica de los personajes del Siglo de Oro. Se trata ante todo, para ellos, de salvaguardar sus intereses económicos, por lo cual no les importa sacrificar la honra, haciendo la vista gorda ante la afrenta que les inflige el seductor de la novela. Lo único que les preocupa es idear una estratagema para hacerse con la herencia del viejo marqués del Corcel.

A lo largo del capítulo, Jardiel procura resaltar tanto la codicia como la tontería de los maridos burlados dando al episodio una clara tonalidad cómica. Tras una semana larga de reflexión, por fin uno de ellos da señales de haber encontrado la solución. A partir de ese momento, la escena se convierte en una secuencia francamente burlesca en la que el narrador saca los mejores efectos cómicos de la torpeza del personaje. De hecho, después de dar un grito, Fritz se da un golpecito en la frente como quien acaba de tener una idea súbita. Todos se precipitan entonces para interrogarle: "Pero Fritz no pudo contestar. Había querido el azar que en el momento de surgirle la idea tuviese una botella de Grand Marnier en la mano y al darse un puñetazo en la frente se arreó con la botella y cayó atrás conmocionado" (Vírgenes: 448).

El personaje vuelve en sí y otra vez cada uno se devana los sesos en busca de alguna idea salvadora. Por supuesto, cuando Fritz se hace con otro frasco de licor, el lector se imagina en seguida que el narrador va a explotar la comicidad de repetición y reproducir el gag anterior, Pero, Jardiel escoge aquí defraudar las expectativas de su lector:

Fritz, que se servía las escurriduras de un tarro de Ginebra, volvió a presentar síntomas de haber tenido otra idea.

Gritó:

-¡Ah! 
Y todos se lanzaron a arrebatarle el tarro de la mano. (Vírgenes: 450$)^{26}$.

Al desactivar el gag de repetición, Jardiel provoca otra clase de risa, una risa más intelectual que nace de la frustración del lector y de la sensación de haber sido manipulado por el autor. Este tipo de gag era el que más agradaba a Chaplin, como da fe de ello esta declaración del actor: "Représenter ce qu’attend le public et faire alors juste autrement est un pur plaisir pour moi”27 (Stourdzé 2005: 32). Cabe notar que, en sus primeros cortos, Charlot no deja de jugar con el espectador, procurando tejer un vínculo de complicidad con él, mediante un gesto significativo, una sonrisa maliciosa o una mirada socarrona ${ }^{28}$. Entre estas marcas enunciativas, Jean-Paul Simon y Daniel Percheron incluyen el gag, por representar este una perturbación del discurso narrativo "normal” (1976: 105). Al provocar un desvío de la atención del espectador respecto a la lógica implícita de la película, el gag bloquea el mecanismo de la absorción diegética, obligando al público a adoptar una actitud distanciada frente a la historia contada. Laurent Le Forestier explica a propósito de ello que "Le cinéma des premiers temps a fait de [la] distanciation l’une des ses principales caractéristiques, là où le cinéma classique ou traditionnel essaye de la gommer pour faciliter l'identification au personnage” (1997: 18) ${ }^{29}$.

El filósofo Henri Bergson señala, por su parte, que la risa se dirige a la inteligencia pura y es incompatible con la emoción: "Le comique exige donc enfin, pour produire tout son effet, quelque chose comme une anesthésie momentanée du coeur" (1969: 4) ${ }^{30}$. Precisamente, tanto las criaturas del cine cómico como los personajes jardielescos son figuras estilizadas, carentes de profundidad psicológica ${ }^{31}$. Entran en la categoría de los “flat characters” según

26. La secuencia termina con una vuelta a la comicidad de gestos y de situación en la más genuina tradición de la Compañía Keystone. Cuando Fritz les comunica su idea, los demás personajes manifiestan tanto entusiasmo que se abalanzan para felicitarle decidiendo llevarlo a hombros como si fuera un verdadero héroe. Pero la gente suele ser inconstante y los maridos burlados no son una excepción, puesto que "de pronto lo soltaron para salir todos corriendo hacia el jardín; con lo cual Fritz se dio un batacazo que él mismo adjetivó de kolossal" (Vírgenes: 451).

27. Representar lo que espera el público y actuar acto seguido de manera totalmente contraria, es un placer para mí.

28. "Il y a quelque chose, en particulier, que Chaplin cherche à conserver du théâtre: un rapport immédiat, complice, de l'acteur et du public, malgré la séparation radicale qu'impose la 'représentation' cinématographique” (Bordat 1997: 118) (Hay algo, en particular, que Chaplin procura recuperar del teatro: una relación directa, cómplice, entre el actor y su público, pese a la separación radical que impone la 'representación' cinematográfica).

29. El cine de los primeros tiempos había hecho de la distanciación una de sus principales características, mientras que el cine clásico o tradicional procuraba anularla para favorecer la identificación con el personaje.

30. Lo cómico, para surtir plenos efectos, exige una como anestesia momentánea del corazón.

31. En su ensayo, Petr Král resalta la carencia de profundidad psicológica, ese “a-psicologismo fundamental” característico de los personajes burlescos (1984: 313). 
la clasificación establecida en 1927 por Edward Morgan Forster en su ensayo titulado Aspects of the Novel. Estas figuras planas carecen de trascendencia y no tienen más ambición que la de hacer reír al público. El narrador de la trilogía nos invita por tanto a considerarlos como meros peleles o muñecos. En el episodio del aseo de Valdivia y en otras muchas secuencias de la trilogía, Jardiel procura bloquear el proceso de identificación afectiva o sentimental, incitándonos a contemplar a sus criaturas con una mirada distanciada, como si mirásemos "con la perspectiva de la otra ribera", igual que en los esperpentos de Valle-Inclán ${ }^{32}$.

De hecho, el personaje del cine cómico está principalmente volcado hacia el exterior, puesto que su misión es imprimir un ritmo lo bastante rápido como para favorecer el encadenamiento de efectos cómicos. Fabrice Revault d'Allonnes señala además que el cine cómico mudo, con su sucesión de movimientos, acciones y reacciones, exacerbaba de modo paródico y crítico el frenesí de la época moderna: "Le cinéma burlesque est lié à un certain type de société, industrieuse et machinique, où les rythmes s'accélèrent, où la confrontation avec l'espace et le temps s'emballe" (1997: 42) ${ }^{33}$. Ahora bien, en Le Rire, Henri Bergson demuestra que un exceso de velocidad puede mover a risa, puesto que "par manque de souplesse, par distraction ou obstination du corps, par un effet de raideur ou de vitesse acquise, les muscles ont continué d'accomplir le même mouvement quand les circonstances demandaient autre chose" (1969: 7; énfasis del autor) ${ }^{34}$.

Jardiel Poncela parece acogerse a esta teoría cuando en el episodio de la seducción de Mignonne, el cuerpo de Zambombo se desvía de su trayectoria y, pasando por la ventana abierta, va a parar a la vía férrea. Sometidos a los efectos de la velocidad o de la precipitación, los personajes de la trilogía se convierten a menudo en pequeños artilugios, a ejemplo de la doncella de Palmera, quien "voló sobre el precioso bimotor de sus pantorrillas con rumbo a la Casa de Socorro" (Espérame: 253). Lo que nace a la vuelta del siglo -escribe Jean-Philippe Tessé- "c’est l'homme mécanisé dont les gestes sont sécables, recomposables et reproductibles à souhait, comme le cinéma, qui est un art mécanique

32. En el prólogo de Los cuernos de don Friolera, don Estrafalario le dice a don Manolito: “yo quisiera ver el mundo con la perspectiva de la otra ribera” (Valle-Inclán 2003: 126).

33. El cine burlesco está vinculado a cierto tipo de sociedad, industriosa y maquínica, en la que los ritmos se aceleran, y la confrontación con el espacio y el tiempo se sale de control.

34. por falta de agilidad, por distracción o por obstinación del cuerpo, por un efecto de rigidez o de velocidad adquirida, han seguido los músculos ejecutando el mismo movimiento cuando las circunstancias exigían otro distinto. 


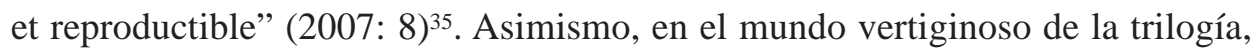
“máquinas y humanos llevados por un mismo frenesí intercambian papeles y atributos, con lo cual asistimos al nacimiento de un ser híbrido, 'mecanizado', 'robotizado’, de ademanes sincopados de autómata” (François 2014: 167). Baste para comprobarlo este ejemplo sacado de Amor se escribe sin hache, en que el protagonista sale de su cuarto de baño "afeitado, bañado, perfumado, vestido y planchado, calzado y charolado” (Amor: 322, énfasis mío). Parece como si saliera de una cadena de montaje o de un monstruoso artilugio versátil que anuncia "The feeding machine" de los Tiempos modernos que Charlie Chaplin había de rodar en 1936.

\section{Conclusión}

Ideada y redactada en el contexto cultural de los felices años 20, la trilogía humorista de Enrique Jardiel Poncela rinde homenaje al cine burlesco mudo, al que muchos de los artistas vanguardistas acogieron con entusiasmo, haciendo además de Charlot un verdadero icono de la modernidad (Lista 2005: 51). El humorista madrileño comparte con los grandes cómicos el gusto por la burla de las convenciones, la subversión de los tópicos y la distorsión paródica. En varios episodios de la trilogía, Jardiel reivindica el gesto iconoclasta de Charlot, al que Emmanuel Dreux define como una "fuerza subversiva en actos" por su afán de derribar todos los valores que ya no tenían cabida en el nuevo mundo en construcción (2007: 154). Lo que recoge Jardiel de Chaplin es su manera de no dar nada por sentado, de no dejarse avasallar por ninguna rutina, y mantenerse receptivo frente a las nuevas técnicas, sin permitir que estas le reste a su estilo un ápice de originalidad (Bordat 1997: 58).

Señala Petr Král que si los artistas del cine mudo ponen todo su empeño en echar por tierra los modelos clásicos, las normas preceptivas, los principios sagrados, es porque son conscientes de que nada es absoluto. En el cine burlesco impera el relativismo a ultranza, afirma el escritor y ensayista checo (1984: 247). Esta noción aparece en el umbral de la trilogía, precisamente en el prólogo de Amor se escribe sin hache, donde Jardiel invita a sus lectores a "pensar en que la verdad no es nunca absoluta" (98; énfasis del autor). Sabiendo que todo es relativo, el joven humorista procura no dárselas de moralista. Frente a los grandes

35. Es el hombre mecanizado, cuyos gestos pueden ser divididos, reconstituidos, reproducidos una y otra vez, a semejanza del cine que es un arte mecánico. 
problemas del hombre y de la sociedad, adopta una actitud distanciada, haciendo suya la observación de Ortega según la cual "nace muerta toda novela lastrada con intenciones trascendentales, sean éstas políticas, ideológicas, simbólicas o satíricas” (1995: 46):

¿Que el fondo del corazón humano es negro?

¡Risa!

¿Que no hay nada en el mundo, ni lo más puro, que no se doblegue al dinero? ¡Risa, risa!

¿Que todo está edificado sobre mentiras asquerosas y mantenido por injusticias eternas? [...]

¡Risa, risa,!

¿Que no hay categorías morales, sino sociales? ¿Que la traición y la envidia son el leit-motiv de la existencia? [...]

¡Risa, risa, risa!... (Vírgenes: 77-78).

Con esta declaración, Jardiel se acerca otra vez a Charlie Chaplin y a muchos cómicos del cine burlesco, quienes concebían los gags como otros tantos actos gratuitos, sin orientación moral precisa. Petr Král apunta al respecto que el único mensaje del cine cómico estriba en la libertad que nos incita a conservar ante cualquier tipo de ideología. Según el ensayista checo, los cortometrajes de Chaplin y de los grandes artistas burlescos de la época dan fe de una lucidez siempre renovada que, lejos de adherirse a una causa determinada, se sustenta en la conciencia de la relatividad de los valores en general ${ }^{36}$. No cabe duda de que, al mantenerse al margen de cualquier compromiso ideológico, Enrique Jardiel Poncela sigue los pasos de los grandes maestros del cine cómico mudo, a la par que logra inscribir su trilogía novelesca en la categoría de la "comicidad absoluta", según la fórmula acuñada por Charles Baudelaire ${ }^{37}$.

\section{Bibliografía}

AMORÓS A. (1991). Luces de candilejas. Los espectáculos en España 18981939. Madrid: Espasa Calpe.

36. “une lucidité sans cesse renouvelée qui, loin d'épouser une cause précise, se nourrit d'une conscience de la relativité des valeurs en général” (Král 1984: 256-257).

37. El poeta francés llama "comicidad absoluta" a aquella que se mantiene ajena a cualquier compromiso ideológico, en contraste con la "comicidad significativa”. 
BAUDELAIRE, C. 1976 (1855). “De l’essence du rire et généralement du comique dans les arts plastiques”. Euvres complètes. Paris: Gallimard.

BERGSON, H. 1969 (1901). Le Rire. Essai sur la signification du comique. Paris: P.U.F.

BONET MOJICA, Ll. (2006). El cine cómico mudo. Un caso poco hablado. Madrid: T\&B Editores.

BORDAT, F. (1997). “Chaplin, le comique cinéaste”. Le Comique à l'écran. CinémAction (82): 51-58.

COURSODON, J-P. (1973). Buster Keaton. Paris: Seghers.

DREUX, E. (2007). Le Cinéma burlesque ou la subversion par le geste. Paris: L'Harmattan.

DU PASQUIER, S. (1970). “Les gags de Buster Keaton”. Communications (15): 132-144.

FAVRE, F. (1995). “Modernité du burlesque”. L’art du Cinéma (8): 1-10.

FIESCHI, J. (1975). “Du muet au parlant: un art perdu”. Cinématographe (14): 26-31. FORSTER, E. M. (2005). Aspects of the Novel. London: Penguin Books.

FRANÇOIS, C. (2014). "Enrique Jardiel Poncela y la novela cosmopolita de principios del siglo XX”. Cuadernos de investigación filológica (40): 149-170.

FRANÇOIS, C. (2011). "Banditi, vendetta, debito di sangue y otros tópicos de la Córcega romántica en ¡Espérame en Siberia, vida mía! de Jardiel Poncela”. Espéculo (46). <http://www.ucm.es/info/especulo/numero46/banditi.html>.

GOLA, G. (1983). "Le comique cinématographique: aspect d'une problématique" en Flashes sur le comique d'images dans le film et dans la B.D. Louvain-laNeuve-Cabay Libraire: 11-42.

HAUSTRATE, G. (1997). Guide du cinéma mondial. 1895-1967. Paris: Syros.

JARDIEL PONCELA, E. 1990 (1928). Amor se escribe sin hache. (Ed. de Roberto Pérez). Madrid: Cátedra.

JARDIEL PONCELA, E. 1992 (1929). ¡Espérame en Siberia, vida mía! (Ed. de Roberto Pérez). Madrid: Cátedra.

JARDIEL PONCELA, E. 1988 (1930). Pero... ¿hubo alguna vez once mil vírgenes? (Ed. de Luis Alemany). Madrid: Cátedra.

JARDIEL PONCELA, E. (1999). Mi padre. Madrid: Biblioteca Nueva.

KRÁL, P. (1984). Le Burlesque, ou Morale de la tarte à la crème. Paris: Stock.

LACASSIN, F. (1995). Maître des lions et des vampires. Louis Feuillade. Paris: Pierre Bordas \& Fils.

LE FORESTIER, L. (1997). "Le cinéma français des premiers temps: comique par essence?” en Le Genre comique. (Eds. C. Rolot y F. Ramirez). Montpellier: Centre d’Etudes du XXe siècle / Université Paul Valéry: 15-32. 
LISTA, G. (2005). “Une nouvelle effigie de l'art”. Chaplin, Beaux Arts Hors-série (12): 49-51.

LOMBEZZI, A. (1983). "Problèmes de codification du comique cinématographique" en Flashes sur le comique d'images dans le film et dans la B.D. Louvain-la-Neuve-Cabay Libraire: 43-61.

MITRY, J. (1972). Tout Chaplin. Paris: Seghers.

MORRIS, C. B. (1993). La acogedora oscuridad. El cine y los escritores españoles (1920-1936). Córdoba: Filmoteca de Andalucía.

NYSENHOLC, A. (1979). L'Age d'or du comique. Sémiologie de Charlot. Bruxelles: Editions de l'Université de Bruxelles.

ORTEGA Y GASSET, J. 1995 (1925). Ideas sobre el Teatro y la Novela. Madrid: Alianza Editorial.

REVAULT D’ALLONNES, F. (1997). “'Prémodernité' du burlesque”. Le Comique à l'écran. CinémAction (82): 39-50.

RIAMBAU, E. (2000). Charles Chaplin. Madrid: Cátedra.

SIMON, J-P. y PERCHERON, D. (1976). “Gag” en Lectures du film. 104-107. STOURDZÉ, S. y TERRIER-HERMANN, V. (dirs.) (2005). Chaplin. Beaux Arts Hors-série (12). Paris: Beaux Arts SAS.

TESSÉ, J-P. (2007). Le Burlesque. Paris: Les Cahiers du Cinéma.

SEGUÍ, J-Ll. y CORT, I. (1998). La estructura del gag. Dos cortometrajes de Charles Chaplin. Valencia: Episteme.

VALLE-INCLÁN, R. del. 2003 (1930). Martes de carnaval-esperpentos. Madrid: Espasa Calpe. 